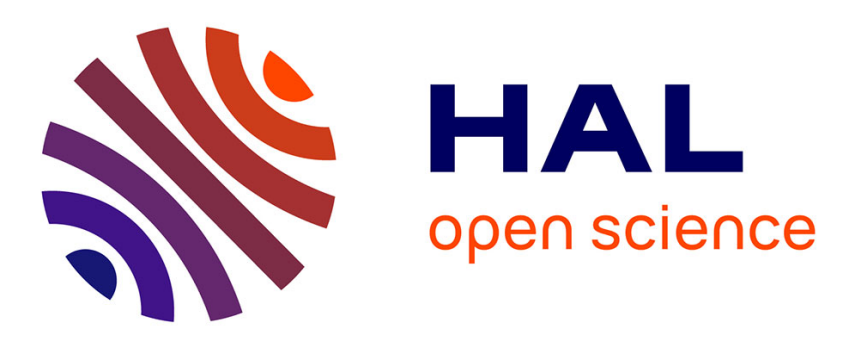

\title{
Inorganic fillers influence on the radiation-induced ageing of a space-used silicone elastomer
}

Aurélien Roggero, Eric Dantras, Thierry Paulmier, Claire Tonon, Sabine

Dagras, Simon Lewandowski, Denis Payan

\section{To cite this version:}

Aurélien Roggero, Eric Dantras, Thierry Paulmier, Claire Tonon, Sabine Dagras, et al.. Inorganic fillers influence on the radiation-induced ageing of a space-used silicone elastomer. Polymer Degradation and Stability, 2016, vol. 128, pp. 126-133. 10.1016/j.polymdegradstab.2016.03.010 . hal01345996

\section{HAL Id: hal-01345996 \\ https://hal.science/hal-01345996}

Submitted on 18 Jul 2016

HAL is a multi-disciplinary open access archive for the deposit and dissemination of scientific research documents, whether they are published or not. The documents may come from teaching and research institutions in France or abroad, or from public or private research centers.
L'archive ouverte pluridisciplinaire HAL, est destinée au dépôt et à la diffusion de documents scientifiques de niveau recherche, publiés ou non, émanant des établissements d'enseignement et de recherche français ou étrangers, des laboratoires publics ou privés. 


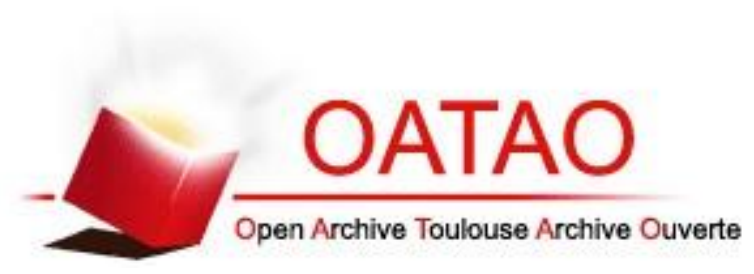

\section{Open Archive TOULOUSE Archive Ouverte (OATAO)}

OATAO is an open access repository that collects the work of Toulouse researchers and makes it freely available over the web where possible.

This is an author-deposited version published in : http://oatao.univ-toulouse.fr/ Eprints ID : 15716

To link to this article : $10.1016 /$ j.polymdegradstab.2016.03.010

URL : http://dx.doi.org/10.1016/j.polymdegradstab.2016.03.010

To cite this version : Roggero, Aurélien and Dantras, Eric and Paulmier, Thierry and Tonon, Claire and Dagras, Sabine and Lewandowski, Simon and Payan, Denis Inorganic fillers influence on the radiation-induced ageing of a space-used silicone elastomer. (2016) Polymer Degradation and Stability, vol. 128. pp. 126-133. ISSN 0141-3910

Any correspondence concerning this service should be sent to the repository administrator: staff-oatao@ listes-diff.inp-toulouse.fr 


\title{
Inorganic fillers influence on the radiation-induced ageing of a space- used silicone elastomer
}

\author{
A. Roggero ${ }^{a}$, E. Dantras ${ }^{a}{ }^{*}$, T. Paulmier ${ }^{b}$, C. Tonon ${ }^{c}$, S. Dagras ${ }^{c}$, S. Lewandowski ${ }^{b}$, \\ D. Payan ${ }^{\mathrm{d}}$
}

a Physique des Polymères CIRIMAT, Université de Toulouse, Université Paul Sabatier, 108 route de Narbonne, Bât. 3R1b2, 31062 Toulouse Cedex 9, France

b ONERA, The French Aerospace Lab, F-31055, France

${ }^{c}$ Airbus Defence and Space, 31 Avenue des Cosmonautes, 31402 Toulouse, France

d Centre National d'Etudes Spatiales, 18 Avenue Edouard Belin, 31400 Toulouse, France

Keywords:

Silicone elastomer

Ionizing radiations

Crosslinking

Inorganic fillers

Solid-state NMR

\begin{abstract}
A B S T R A C T
A space-used filled silicone rubber (silica and iron oxide fillers) and its polysiloxane isolated matrix were exposed to high energy electrons in order to determine their ageing mechanisms from a structural point of view. Physicochemical analysis evidenced that both filled and unfilled materials predominantly crosslink under such irradiation. Solid-state ${ }^{29} \mathrm{Si}$ NMR spectroscopy allowed the identification of T-type $\mathrm{SiO}_{3}$ units as the main new crosslinks formed in the polymer network. It also revealed an increase in Qtype $\mathrm{SiO}_{4}$ units in the irradiated filled sample. Thanks to the combination of NMR spectroscopy and ammonia-modified swelling tests, these Q-type units were associated with new crosslinks formed at the silica fillers-matrix interface. While the main interaction between the polysiloxane network and the fillers was shown to proceed mainly through hydrogen bonding in the pristine filled samples, it was suggested that the hydrogen bonds were progressively replaced with $\mathrm{SiO}_{4}$ chemical bonds. These additional chemical crosslinks induced evolutions of the shear modulus on the rubber plateau and crosslink density that were significantly more pronounced in the filled material than in the neat one.
\end{abstract}

\section{Introduction}

In space applications, the ageing of surface dielectric materials is a main concern as it may lead to spacecraft failures and mission degradation. In 2009, a study carried on a panel of 129 spacecrafts showed that $45 \%$ of total on-orbit spacecraft failures were due to electrical malfunction [1]. Solar arrays in particular, were incriminated in $20 \%$ of total failures. Due to the high power density available in these power generators, the triggering of a small electrostatic discharge may lead to catastrophic maintained arc, resulting in the permanent degradation of solar cells [2].

Room Temperature Vulcanization (RTV) silicone elastomers are extensively used for solar array assembly [3], mainly as adhesives (solar cells, cover glasses, electrical wires) and sealants. Not only the mechanical properties of these elastomers will significantly evolve due to interaction with ionizing radiations [4], but others physical properties such as electrical conductivity may also vary.
Precise knowledge of silicone elastomers ageing tendencies in the space environment is therefore prerequisite for failure anticipation over the spacecraft lifetime (15 years).

From the 1950s, just like every known polymer, polydimethylsiloxane (PDMS) has been irradiated with multiple sources of ionizing radiations in order to determine its ageing mechanisms: gamma rays [5-7], ultraviolet light $[8,9]$, electrons $[4,10]$ and protons $[11,12]$. Since then, it has been acknowledged that silicone materials predominantly crosslink when exposed to ionizing radiations (as opposed to degradation when predominant chain scission is observed) [13]. Moreover, ionizing dose has been believed to be the principal parameter governing the increase in crosslink density. In the case of PDMS, Charlesby [14] suggested that predominant side-chain fractures ( $\mathrm{Si}-\mathrm{C}$ and $\mathrm{C}-\mathrm{H}$ bonds) under irradiation lead to the formation of $\mathrm{Si}^{\bullet}, \mathrm{CH}_{2} \cdot$ and $\mathrm{CH}_{3} \cdot$ radicals. By means of infrared spectroscopy, Miller experimentally evidenced the formation of silmethylene $\left(\mathrm{Si}-\mathrm{CH}_{2}-\mathrm{Si}\right)$, silethylene $(\mathrm{Si}-\odot$ $\mathrm{CH}_{2}-\mathrm{CH}_{2}-\mathrm{Si}$ ) and $\mathrm{Si}-\mathrm{Si}$ crosslinks under electron irradiations, with $\mathrm{G}$-values (radiation chemical yield, which in this case represents the number of crosslinks formed per $100 \mathrm{eV}$ dissipated in the 
material [15]) of 1.8, 0.5 and 1.1 respectively [16]. In 2002, Hill et al. used solid-state ${ }^{29} \mathrm{Si}$ NMR spectroscopy to characterize the new structures created under gamma irradiation. They observed the formation of new T-type crosslinks $\left(\mathrm{SiO}_{3}\right)$ with a $\mathrm{G}$-value of 1.7. In the meantime, they determined a $\mathrm{G}$-value of 0.34 for silmethylene crosslinks, that is much less than the value of 1.8 reported by Miller [16]. They also evidenced the formation of Si-H bonds.

The structural evolution of linear PDMS under irradiation is therefore well documented. These materials, however, are most often filled with inorganic particles in order to enhance their mechanical (increased tear resistance, reduced thermal expansion in bonded assemblies) [17,18], thermal [19] or electrical (surface charge dissipation) [20] properties. Fillers also may ease the implementation of the materials on spacecrafts (increased viscosity or dyeing). How the presence of such fillers in the silicone matrix impacts the degradation of the material is little-known. Stevenson et al. studied the influence of silica fillers on the ageing of a PDMS rubber [21] and observed a much stronger increase in apparent crosslink density in the filled samples than in the unfilled one. To account for this discrepancy, the formation under irradiation of new crosslinks at the polymer-silica interface was suggested. Other authors came to a similar conclusion by performing ammoniamodified swelling tests [22] or by using solid-state ${ }^{29} \mathrm{Si}$ NMR spectroscopy [23]. Other suggested an increase in hydrogen bonding at the matrix-fillers interface [24].

This study consists in determining the ageing mechanisms of a space-used commercial filled silicone elastomer exposed to high energy electron irradiations. It is focused on evidencing the evolution of the fillers-matrix bonding nature (physical or chemical) that has been previously discussed in literature.

\section{Materials and methods}

\subsection{Materials}

The studied material is a commercial (Wacker) bi-component silicone elastomer which crosslinks at room temperature. Part A mainly consists of a polymethylphenylsiloxane resin (approx. $35 \mathrm{wt}$ $\%$ ) mixed with crystalline silica ( $\alpha$-quartz particles of the glass splinter type, the size of which is comprised in the range [0.2; $20 \mu \mathrm{m}]$ ) and iron(III) oxide (spherical particles in the range [0.1; $1 \mu \mathrm{m}]$ ) fillers. Part B is a hardener containing a Pt catalyst responsible for the polymerization. The two components are manually mixed (weight ratio 9:1, according to data sheet) and poured into a mold consisting of a $50 \times 50 \mathrm{~mm}^{2}$ aluminum substrate the borders of which had been covered with aluminum tape. Even though this material is able to crosslink at room temperature, a curing process of $6 \mathrm{~h}$ at $100{ }^{\circ} \mathrm{C}$ was performed after mixing in order to enhance sample reproducibility.

A filtering process performed on part A allowed separation and removal of the fillers from the resin. Consecutive polymerization with unmodified part B allowed the elaboration of neat samples (no fillers), as opposed to filled unmodified samples (with fillers).

\subsection{Differential scanning calorimetry}

Differential scanning calorimetry (DSC) measurements were performed with a TA Instruments apparatus under helium. The samples (mass $\sim 10 \mathrm{mg}$ ) were analyzed in a sealed aluminum pan, at a heating rate of $20{ }^{\circ} \mathrm{C} \mathrm{min}{ }^{-1}$. Glass transition temperatures were determined at half-height of the heat capacity jump during a temperature ramp from $-150{ }^{\circ} \mathrm{C}$ up to $20^{\circ} \mathrm{C}$.

\subsection{Dynamic mechanical analysis}

The dynamic mechanical analysis (DMA) was performed under nitrogen on a Rheometrics Scientific ARES G2 manufactured by TA Instruments. $300 \mu \mathrm{m}$-thick adhesive films were analyzed in the parallel plates configuration (aluminum plates of diameter $8 \mathrm{~mm}$ ), over the linear elastic range. Torque was measured at constant strain $(\gamma=0.1 \%)$ and constant angular frequency $\left(\omega=1 \mathrm{rad} \mathrm{s}^{-1}\right)$ allowing the determination of the complex shear modulus $G^{*}(\omega, T)$ (eq. (1)).

$G^{*}(\omega, T)=G^{\prime}(\omega, T)+i G^{\prime \prime}(\omega, T)$

where $G^{\prime}$ and $G^{\prime \prime}$ are the conservative and dissipative moduli, respectively.

A high axial compression force (6.37 N) was constantly applied during the measurements in order to ensure consistent pressure on the sample surface, and to prevent sliding at the interface between the sample and the metal plates.

\subsection{Solid-state NMR spectroscopy}

Single pulse solid-state NMR spectra were acquired at room temperature using a Bruker Advance 400 spectrometer equipped with a $4 \mathrm{~mm}$ probe operating at $79.4 \mathrm{MHz}$ for ${ }^{29} \mathrm{Si}$. Rubber film samples were cut in small pieces and packed $(\mathrm{m} \sim 100 \mathrm{mg})$ into a zirconium dioxide rotor oriented at the magic angle (54.74 ) with a spinning frequency of $8 \mathrm{kHz} .{ }^{29} \mathrm{Si}$ SP-MAS (single pulse magic angle spinning) experiments were performed with a pulse time of $3 \mu \mathrm{s}$ and a long recycle delay of $200 \mathrm{~s}$. The latter was chosen after a parametric study that showed that below 200 s, all excited entities had not fully relaxed, resulting in varying ratios between the observed peaks. ${ }^{1} \mathrm{H}^{29} \mathrm{Si}$ CP-MAS (cross-polarization magic angle spinning) were performed with a contact time of $2 \mathrm{~ms}$ and a recycle delay of $3 \mathrm{~s}$. All of the chemical shifts are relative to TMS.

\subsection{Solvent swelling}

Standard swelling tests were performed in toluene. The ammonia-modified solvent swelling procedure, initially presented by Polmanteer and Lentz [25] and applied by Chien et al. [24] to the study of filled polysiloxane rubbers, was also used for its ability to disrupt potential hydrogen bonding occurring between surface silanol groups on the silica fillers and oxygen atoms of the polysiloxane backbone.

The samples were first weighed ( $\mathrm{m} \sim 100 \mathrm{mg}$ ) and submerged in an excess of toluene. Due to the solvent penetrating the polymer network, the samples progressively swelled, resulting in increasing mass. On a periodic basis, samples were taken out from the toluene bath, rapidly dried using absorbing paper, weighed and put back in toluene, until their mass became constant meaning the samples were fully swollen in toluene. At that moment, an excess of concentrated ammonia solution $\left(\mathrm{NH}_{4} \mathrm{OH}, 30 \mathrm{wt} \%\right)$ was added to the toluene bath. The previous periodic drying/weighing process was repeated until equilibrium was reached again (final swollen mass, $\mathrm{m}_{\text {swollen }}$ ). They were then let to dry in a fume hood at ambient temperature for two days and weighed again (final dry mass, $\mathrm{m}_{\mathrm{dry}}$ ).

The volume fraction $v_{2}$ of polymer in the swollen network is related to $\mathrm{m}_{\text {swollen }}$ and $\mathrm{m}_{\mathrm{dry}}$ through eq. (2).

$\nu_{2} \stackrel{\text { def }}{=} \frac{V_{\text {dry }}}{V_{\text {Swollen }}}=\frac{\frac{m_{\text {swollen }}}{d_{\text {pol }}}}{\frac{m_{\text {swollen }}-m_{\text {dry }}}{d_{\text {solvent }}}+\frac{m_{\text {swollen }}}{d_{\text {pol }}}}$

where $V_{\text {dry }}$ and $V_{\text {swollen }}$ are the dry and swollen sample volumes, 
$\mathrm{d}_{\text {pol }}$ and $\mathrm{d}_{\text {solvent }}$ the polymer and solvent densities.

Regarding filled samples, filler masses were calculated ( $59 \mathrm{wt}$ $\%)$ and subtracted from measured swollen and dry masses. The density of the neat material (0.99) was then used in the calculation of $v_{2}$.

Molecular weights between crosslinks (Mc) were calculated using the Flory-Rehner equation [26] (eq. (3)).

$M_{C}=-\frac{d_{p o l} V_{1}\left(\nu_{2}^{\frac{1}{3}}-\frac{\nu_{2}}{2}\right)}{\ln \left(1-\nu_{2}\right)+\nu_{2}+\mu \nu_{2}^{2}}$

where $\mathrm{V}_{1}$ is the molar volume of toluene $\left(106.3 \mathrm{~cm}^{3} \mathrm{~mol}^{-1}\right.$ [27]) and $\mu$ the Flory-Huggins PDMS/toluene interaction parameter (0.791 [27]).

Crosslink density $\rho$ was finally calculated (eq. (4)) as the reciprocate Mc normalized to the molecular weight of the PDMS monomer unit MPDMS $\left(72 \mathrm{~g} \mathrm{~mol}^{-1}\right)$.

$\rho=\frac{M_{P D M S}}{M_{C}}$

\subsection{Electron irradiations}

Electron irradiations were performed under secondary vacuum in the SIRENE facility at ONERA. $150 \mu \mathrm{m}$-thick elastomer films were irradiated using a $400 \mathrm{keV}$ Van de Graaff electron gun along with a scattering foil in order to uniformly expose the sample surface. Ionizing doses of $3.810^{5} \mathrm{~Gy}$ and $1.410^{6} \mathrm{~Gy}$ were both achieved in less than $12 \mathrm{~h}$ thanks to high beam currents of order of $10 \mathrm{nA} \mathrm{cm}{ }^{-2}$. No mechanical constraint was applied during the irradiation procedure.

Ionizing dose $\mathrm{D}$ expressed in Grays $\left(1 \mathrm{~Gy}=1 \mathrm{~J} \mathrm{~kg}^{-1}\right)$ is defined by eq. (5).

$D=\Phi \frac{1}{d}\left(\frac{d E}{d x}\right)$

where $\Phi$ is the particle fluence (in $\mathrm{cm}^{-2}$ ), $\mathrm{d}$ the material density and $\mathrm{dE} / \mathrm{dx}$ the energy lost by an incident particle by unit length travelled in the material.

Energy loss $(\mathrm{dE} / \mathrm{dx})$ is called mass stopping power (or linear energy transfer) when normalized to the material density. It is mainly dependent on the energy of the incident particle, the atomic number of the material constitutive atoms (heavier nuclei have more interactions with incident particles than lighter nuclei) and the density of the material. The energy loss of $400 \mathrm{keV}$-electrons in silicone was estimated by performing Monte-Carlo simulations with the Casino software [28]. For the sake of simplicity, silicone was approximated as a form of silica $\left(\mathrm{SiO}_{2}\right)$ associated with its experimental density ( 1.4 for the filled material and $\sim 1.0$ for the neat one).

Two dose-depth profiles resulting from the interaction of $400 \mathrm{keV}$-electrons with a $150 \mu \mathrm{m}$-thick silicone film are represented in dash lines in Fig. 1. They correspond to two different exposure times at a flux of $10 \mathrm{nA} \mathrm{cm}{ }^{-2}$. The deposited ionizing dose is homogeneous over the thickness of the silicone film. In the geostationary (GEO) orbit, however, the electrons energy are distributed over a wide range of energies and fluxes (the lowenergy electrons have the higher fluxes). The omnidirectional monoenergetic electron fluxes in GEO orbit were obtained by using the IGE-2006 model [29]. For discrete electron energies over the range $[1 \mathrm{keV}, 1 \mathrm{MeV}]$, the stopping power of silicone was simulated in Casino and the electron flux obtained from IGE-2006. A simple

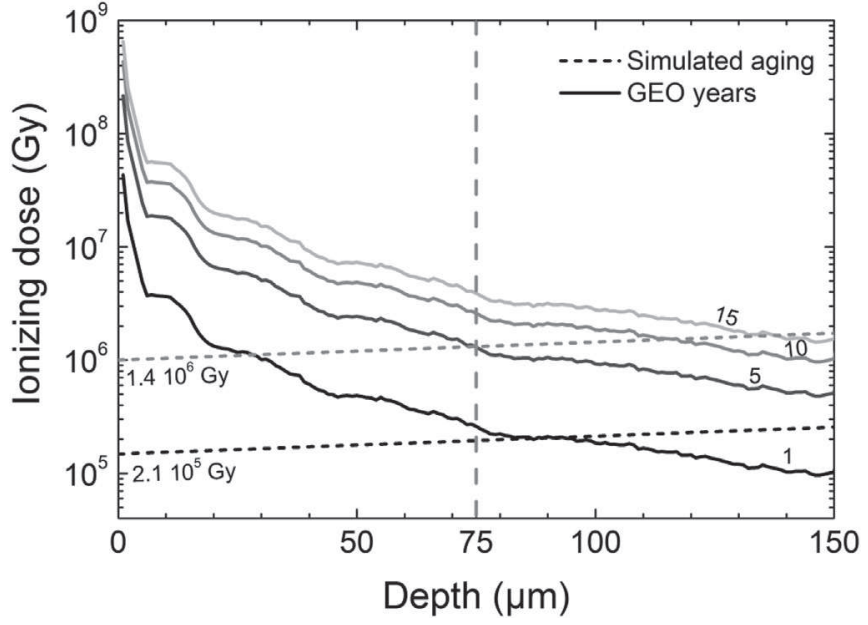

Fig. 1. Dose-depth profiles calculated for experimental electron irradiations (dashed lines) and years of exposure to the geostationary electron environment (lines).

algorithm was then developed in order to combine and integrate the stopping powers and electron fluxes over the energy range, thus giving dose-depth profiles for silicone in the electron GEO electron environment. Fig. 1 shows that the GEO dose-depth profiles are much less homogeneous over the sample thickness than the experimental ones. The dose at the exposed surface is indeed about 3 orders of magnitude greater than at the opposed surface.

According to our calculations and as a first approximation, the experimental ionizing doses represented in Fig. 1 respectively correspond to 1 and 5 year exposures to the GEO orbit in the middle of a $150 \mu \mathrm{m}$-thick silicone film. In these conditions the ageing accelerating factor is thus typically of a few 1000 .

\section{Results}

\subsection{Dynamical mechanical analysis}

The evolution with absorbed ionizing dose of the conservative shear modulus $\mathrm{G}^{\prime}$ measured on the rubber plateau (at $30{ }^{\circ} \mathrm{C}$ ) is represented in Fig. 2, for filled and neat samples. In both cases, $\mathrm{G}^{\prime}$ increases with ionizing dose, but this behavior is emphasized when

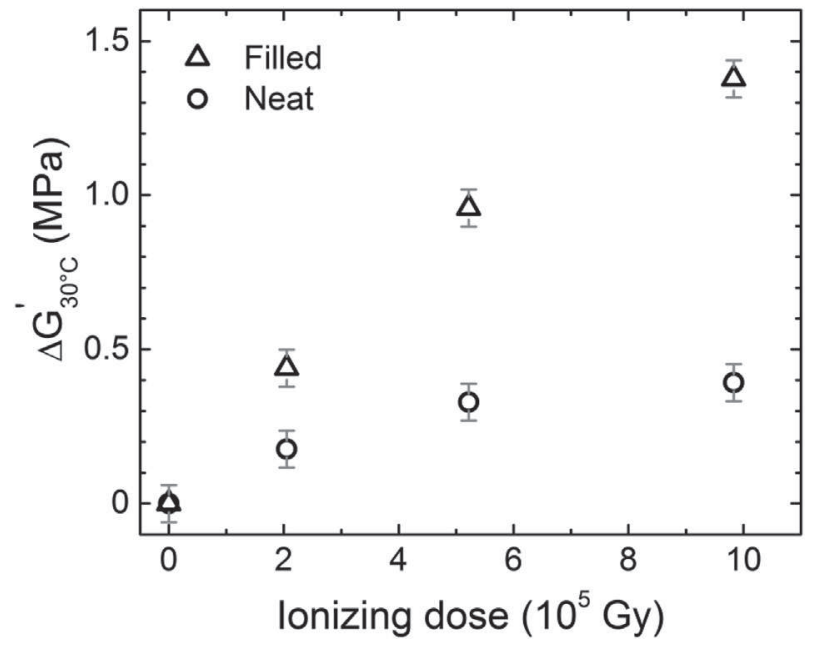

Fig. 2. Evolution of conservative shear modulus on the rubber plateau $\left(30^{\circ} \mathrm{C}\right)$ with ionizing dose for neat and filled samples. 
fillers are incorporated in the polysiloxane matrix. A similar discrepancy was observed by Stevenson et al. [21] by means of tensile tests.

\subsection{Differential scanning calorimetry}

DSC thermograms of irradiated filled silicone samples are represented in Fig. 3. As the ionizing dose increases, the glass transition temperature $T_{g}$ increases, the heat capacity jump at $T_{g}$ decreases and its associated slope decreases. The increase in $\mathrm{T}_{\mathrm{g}}$, represented in the inset of Fig. 3, seems linear over the experimental ionizing dose range with the same slope for both filled and neat samples.

\subsection{Solid-state ${ }^{29}$ Si NMR spectroscopy}

Solid-state ${ }^{29}$ Si NMR SP-MAS (Single Pulse-Magic Angle Spinning) was performed on a pristine and two irradiated $\left(3.610^{5}\right.$ and $9.810^{5} \mathrm{~Gy}$ ) neat samples. The resulting spectra, normalized to sample mass, are represented in Fig. 4. Peak assignments to silicone structural units have been reported from literature in Table 1.

A linear area increase in the peak at $-67 \mathrm{ppm}$ was observed with ionizing dose (290\% for the highest ionizing dose level), which was attributed to the densification of T-type $\left(\mathrm{SiO}_{3}\right)$ units. A linear area decrease of the $-47 \mathrm{ppm}$ peak was also observed (17\% for the highest level), associated with a decrease in phenyl side groups due to bond scission under irradiation, with probable benzene outgassing [30].

Neither the -22 ppm peak, associated with the backbone Dtype $(\mathrm{Si}-\mathrm{O})$ unit, nor the $+8 /+7$ doublet, associated with the Mtype network end groups, significantly evolved under irradiation.

The appearance at the intermediate dose level followed by the disappearance at the highest dose level of a small peak at $-37 \mathrm{ppm}$ was associated to the formation of $\mathrm{Si}-\mathrm{H}$ side groups as already observed in literature [16,31], but its disappearance at the highest level suggest their consecutive dissociation.

Solid-state NMR spectroscopy was also performed in the cross polarization (CP-MAS) mode on the pristine and irradiated neat samples. These spectra are represented in Fig. 5. In the pristine case, only one peak was observed at $-22 \mathrm{ppm}$, which was attributed to the backbone $\mathrm{D}$ unit. As a result of ionizing irradiation, an increase in this peak area and the progressive emergence of the other peaks visible in the SP-MAS spectra were observed.

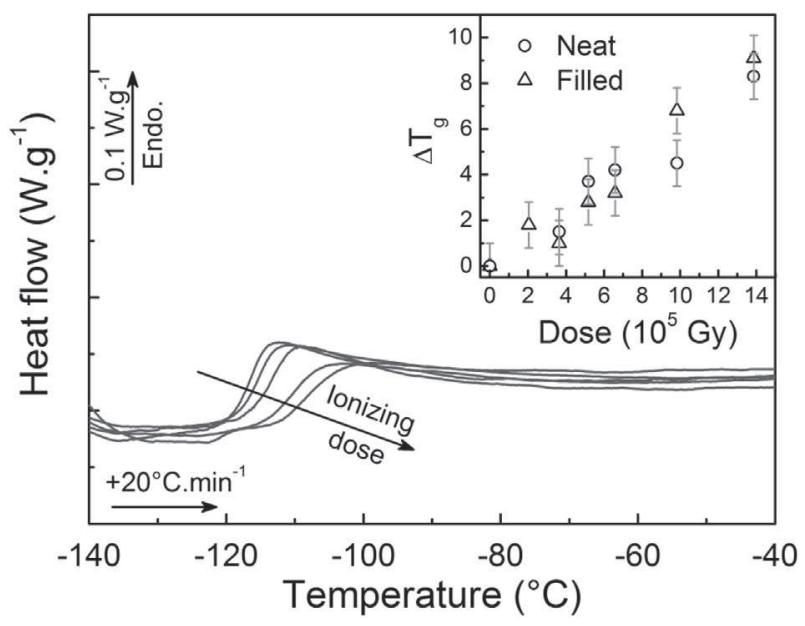

Fig. 3. DSC scans performed on irradiated filled samples and $\mathrm{T}_{\mathrm{g}}$ evolution with ionizing dose for neat and filled materials (inset).

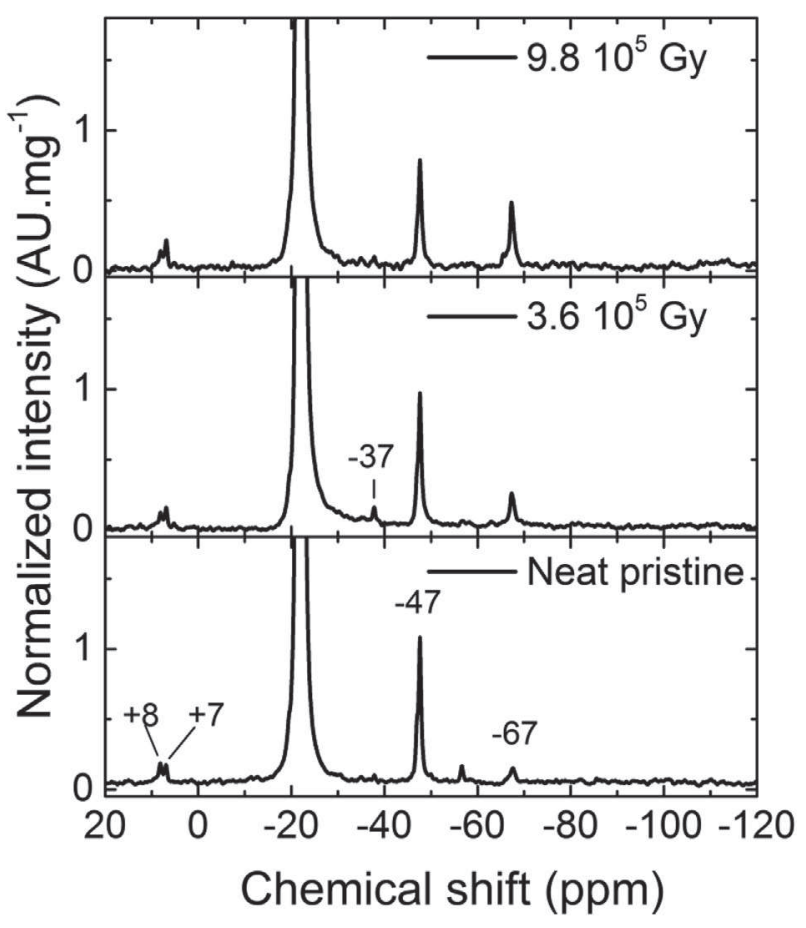

Fig. 4. Solid-state ${ }^{29}$ Si NMR (single pulse MAS) spectra of pristine and irradiated neat samples.

The same solid-state NMR spectroscopy measurements were performed on a pristine and an irradiated $\left(9.810^{5} \mathrm{~Gy}\right)$ filled samples. The associated SP-MAS and CP-MAS spectra are represented in Fig. 6 and Fig. 7, respectively.

The peaks observed in Figs. 4 and 5, associated with the polysiloxane network, were also observed in the spectra of filled samples. In the case of the pristine sample, the incorporated fillers $(\sim 59 \mathrm{wt} \%)$ reduced the signal-to-noise ratio of the latter peaks due to a decrease in polymer content in the sample, and led to the appearance of a peak at $-107 \mathrm{ppm}$ associated with silica-like Qtype $\left(\mathrm{SiO}_{4}\right)$ units.

Like in the neat material case, the peak area at $-67 \mathrm{ppm}$ increased under irradiation but this increase could not be quantified as the peak did not appear in the pristine reference spectrum. A slight decrease ( $6 \%$ ) in peak area at $-47 \mathrm{ppm}$ (phenyl side groups) was also observed. The new peak at $-107 \mathrm{ppm}$ attributed to silicatype bonds greatly increased $(\sim 230 \%)$ as a consequence of irradiation.

It should be noted that approximations were made in the calculation of ionizing dose in order to allow the computation of stopping power. Both neat and filled materials were considered as homogeneous silica $\left(\mathrm{SiO}_{2}\right)$ associated with their experimental density. If the neat material is indeed homogeneous, the filled one is highly heterogeneous as it is composed of a polysiloxane matrix and two kinds of fillers (silica and iron oxide). Therefore, quantitative comparison in the peak evolutions between filled and neat samples should be avoided as the absorbed ionizing dose may differ between the two materials for the same conditions of exposure.

The CP-MAS spectra of the filled samples (Fig. 7) showed the same trends as the neat ones: a progressive increase in all the peaks, with the exception of the peak at $-107 \mathrm{ppm}$ not evidenced in CP-MAS due to the lack of surrounding hydrogen atoms preventing magnetization transfer from protons to silicon spins. 
Table 1

Solid-state ${ }^{29} \mathrm{Si}$ NMR chemical shifts assignments to structural units in silicone [32-34].

\begin{tabular}{ll}
\hline Chemical shift $(\mathrm{ppm})$ & Unit \\
\hline$+7,+8$ & $\mathrm{M}:$ network endings with three methyl side groups \\
-22 & $\mathrm{D}:$ siloxane backbone $(\mathrm{Si}-\mathrm{O})$ \\
-47 & $\mathrm{D}^{\mathrm{Ph}}$ : siloxane backbone $(\mathrm{Si}-\mathrm{O})$ with 2 phenyl side groups \\
-67 & $\mathrm{~T}:$ tri-oxygenated silicon crosslink $\left(\mathrm{SiO}_{3}\right)$ \\
-107 & $\mathrm{Q}:$ crosslinked silicate framework $\left(\mathrm{SiO}_{4}\right)$ \\
\hline
\end{tabular}

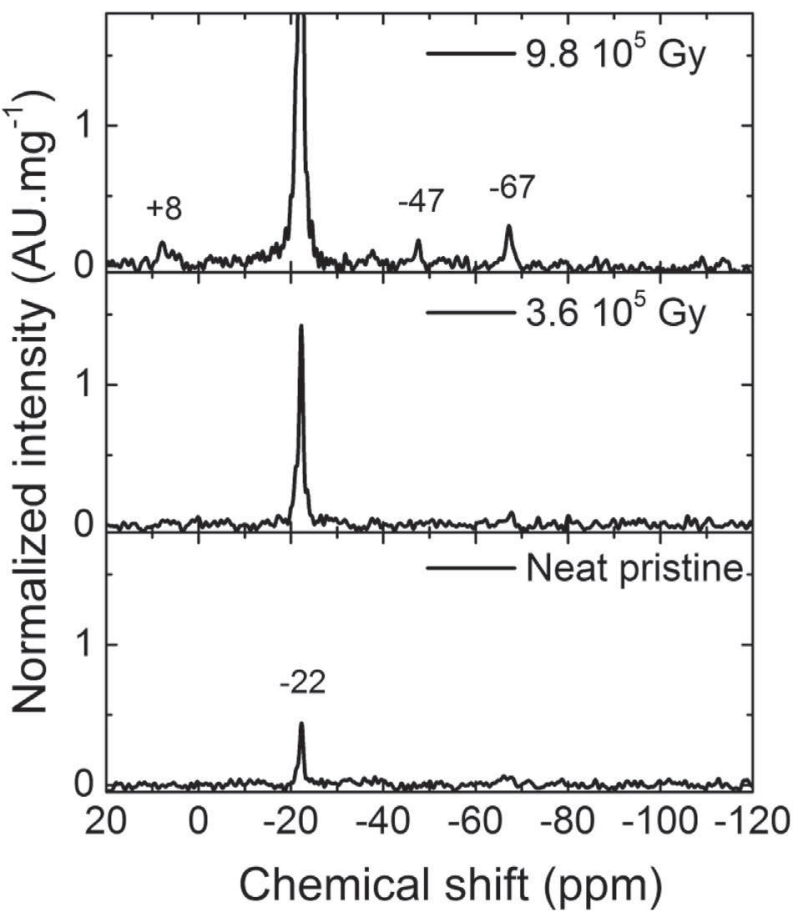

Fig. 5. Solid-state ${ }^{29} \mathrm{Si}$ NMR (cross-polarization MAS) spectra of pristine and irradiated neat samples.

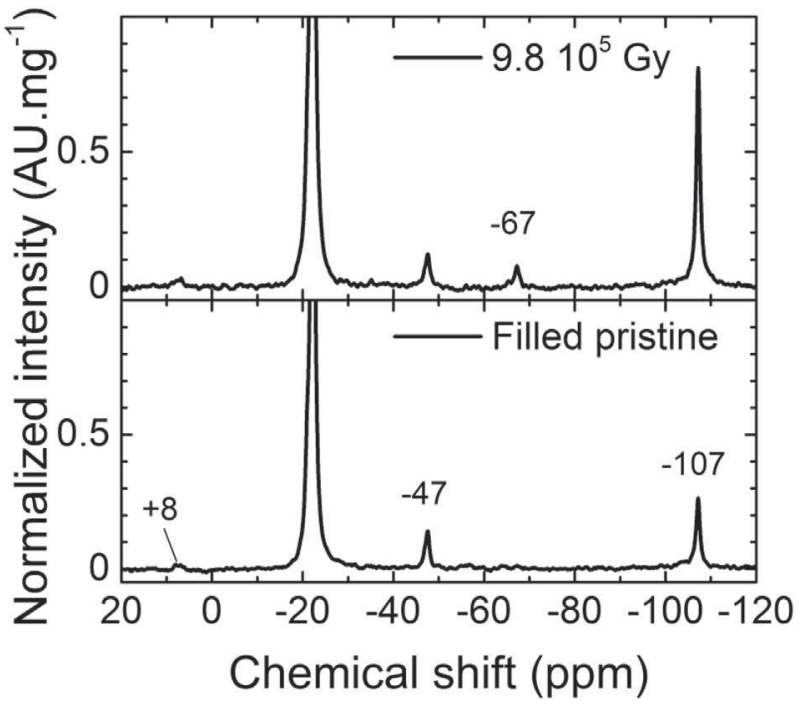

Fig. 6. Solid-state ${ }^{29} \mathrm{Si} \mathrm{NMR}$ (single pulse MAS) spectra of pristine and irradiated filled samples.

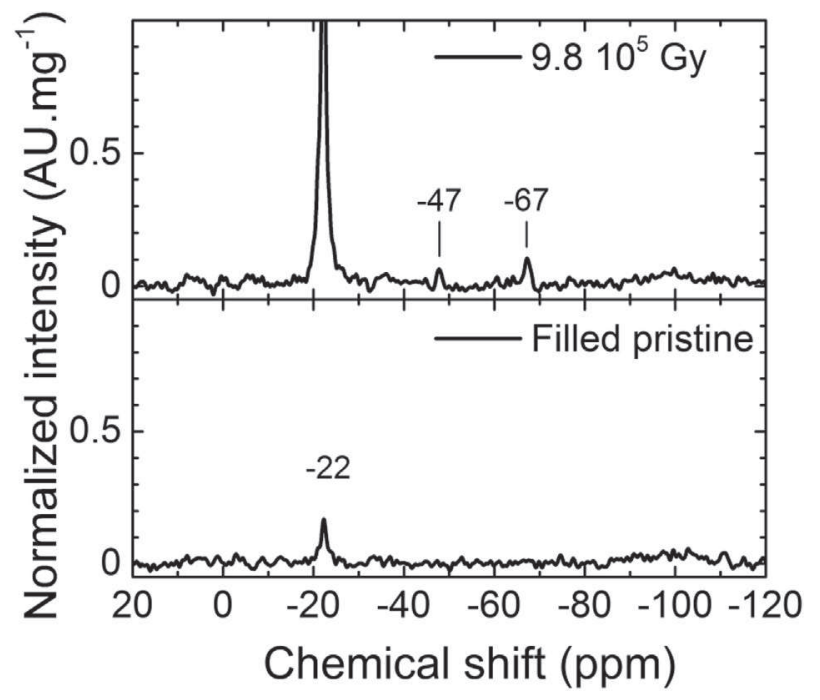

Fig. 7. Solid state ${ }^{29} \mathrm{Si}$ NMR (cross-polarization MAS) spectra of pristine and irradiated filled samples.

\subsection{Swelling studies}

Toluene and ammonia-modified swelling tests were performed on neat and filled irradiated samples.

In the pristine neat case, the influence of ammonia addition to the swelling procedure was estimated negligible as the uncertainty intervals of average molecular weight between crosslinks $M_{c}$ overlapped. On the contrary, the addition of ammonia induced an increase of $500 \%$ for $M_{c}$ of the pristine filled samples (see Fig. 8).

$\mathrm{M}_{\mathrm{C}}$ is represented as a function of ionizing dose in Fig. 9 for neat and filled materials. A decrease in $\mathrm{M}_{\mathrm{C}}$ with increasing ionizing dose was observed with both neat and filled materials. A linear increase

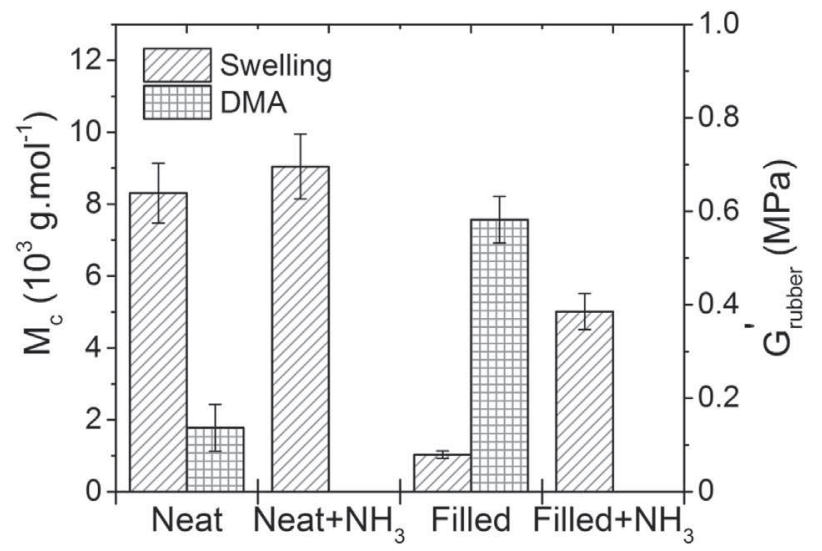

Fig. 8. $M_{c}$ (swelling tests in toluene and ammonia-toluene solution) and $G^{\prime}$ on the rubber plateau (DMA at $30^{\circ} \mathrm{C}$ ) for pristine neat and filled samples. 


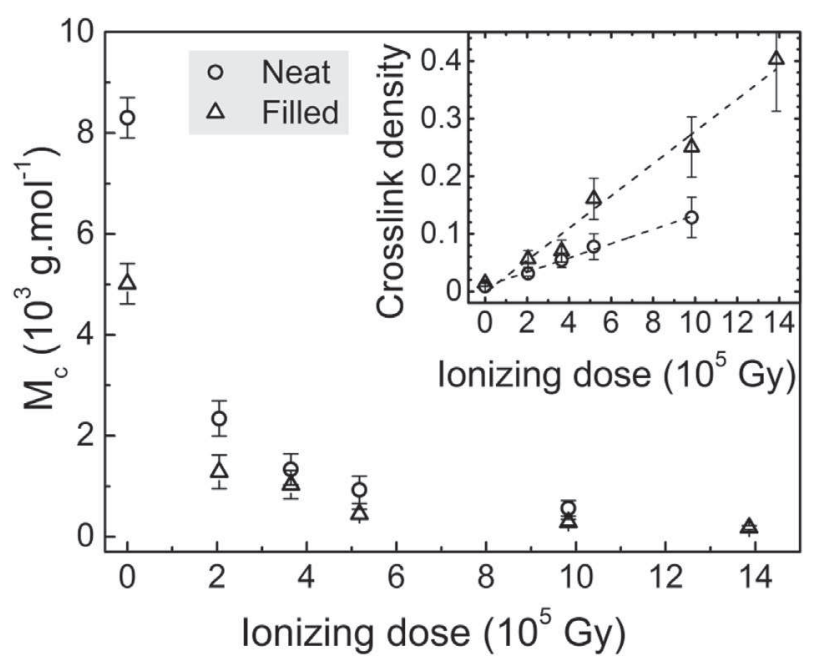

Fig. 9. $M_{c}$ and crosslink density (inset) evolution with ionizing dose for neat and filled samples after swelling tests in toluene (neat, $\bigcirc$ ) and ammonia/toluene (filled, $\Delta$ ). Dashed lines are represented as a guide for the eye.

in the associated crosslink density was observed over the studied ionizing dose range (inset of Fig. 9). Nevertheless, a significant discrepancy between the swelling behaviors of filled and neat materials was noticed: the slope of the crosslink density of the filled material increased more than that of the neat material.

\section{Discussion}

\subsection{Ionizing radiation-induced ageing of the polysiloxane matrix}

The conservative shear modulus of the neat material (DMA, Fig. 2) increased with ionizing dose, which directly evidences a predominant crosslinking process under high energy electron irradiation. The predominance of the crosslinking process, as opposed to scission, was expected as silicone materials are known to predominantly crosslink when exposed to any type of ionizing radiations [13].

DSC (increasing $T_{g}$ with increasing ionizing dose, Fig. 3) and swelling tests (increasing crosslink density with increasing ionizing dose, Fig. 9) results are coherent with the predominance of a crosslinking process. DSC thermograms (Fig. 3) also show that crosslinks densification during irradiation leads to a decrease in the heat capacity jump at $\mathrm{T}_{\mathrm{g}}$ as a consequence of structural stiffening, and in the slope of the jump which can be associated with network segmental lengths heterogeneization [35].

Over the studied ionizing dose range, these evolutions are linear with ionizing dose which is in good agreement with Delides and Shepherd [36] that reported a linear evolution of the crosslink density of a PDMS exposed to $\gamma$-rays up to $1.610^{6} \mathrm{~Gy}$ (sublinear above). The observed sublinear evolution of the mechanical modulus with respect to ionizing dose (Fig. 2) might be due to different factors. First, an important constant axial force $(6.37 \mathrm{~N})$ was applied to the sample during the DMA measurements so as to prevent sliding at the sample-plates interface due to surface smoothing under irradiation (it is reminded however that no mechanical strain was applied to the samples during the irradiation procedure). Then, the absorbed dose was less homogeneous over the volume of the DMA samples due to their higher thickness $(300 \mu \mathrm{m})$ than the $150 \mu \mathrm{m}$-thick samples used with the other techniques. Finally, the physical relationship between the structure of a rubber network and its mechanical properties is complex and appropriate analytical equations to describe it are lacking at the moment.

CP-MAS ${ }^{29} \mathrm{Si}$ NMR results also concur with a predominant crosslinking process. With this technique, there is a magnetization transfer from the protons to the silicon spins. The presence of hydrogen nuclei is therefore prerequisite for such magnetization transfer, but the latter is also greatly influenced by the mobility of the concerned atoms: high molecular mobility leads to heteronuclear dipolar coupling being averaged by molecular motions [37]. As a first approximation the hydrogen content of the material may be considered constant throughout material ageing (outgassing of $\mathrm{H}_{2}, \mathrm{CH}_{4}$ and $\mathrm{C}_{2} \mathrm{H}_{6}$ is generally observed during the radiolysis of PDMS $[13,30]$ but it should hinder rather than enhance crosspolarization). Thus, by improving ${ }^{1} \mathrm{H}^{29} \mathrm{Si}$ magnetization transfer, the crosslinking induced stiffening of the rubber network primarily accounts for the progressive emergence from background noise of the various peaks in the CP-MAS spectra of the irradiated neat material (Fig. 5).

SP-MAS ${ }^{29} \mathrm{Si}$ NMR spectra of the irradiated neat samples evidenced one major evolution with increasing ionizing dose, which was the increasing -67 ppm peak area with increasing ionizing dose. It is associated with a densification of trifunctional $\mathrm{SiO}_{3}$ bonds (T-type units) by a probable mechanism involving both side group bond scission and backbone scission. Hill et al. [32] showed that the formation of T-type crosslinks was predominant over silmethylene, silethylene or Si-Si crosslinks generally accepted before $[14,16]$. The solid-state NMR measurements performed in this study are in good agreement with Hill et al. as no evidence of the formation of $\mathrm{Si}-\mathrm{CH}_{2}-\mathrm{Si}(-28.6 \mathrm{ppm}), \mathrm{Si}-\mathrm{CH}_{2}-\mathrm{CH}_{2}-\mathrm{Si}(-23 \mathrm{ppm}$, overlapping with the $-22 \mathrm{ppm}$ peak associated with the network backbone bond) nor $\mathrm{Si}-\mathrm{Si}(-55 \mathrm{ppm})$ was noticed.

It can be noted that these crosslinks formed during irradiation are different from the silethylene $\left(\mathrm{Si}-\mathrm{CH}_{2}-\mathrm{CH}_{2}-\mathrm{Si}\right)$ resulting from the initial curing process that starts right after the mixing of the two components. However, the small peak at $-67 \mathrm{ppm}$ on the pristine neat SP-MAS spectrum (Fig. 4) indicates the presence of a small amount of T-type crosslinks in the pristine state, which might be a consequence of the curing process at $100{ }^{\circ} \mathrm{C}$ during $6 \mathrm{~h}$.

\subsection{Filler influence on the radiation-induced ageing of the filled material}

The matrix of the filled material corresponds to the neat material to which $\sim 59 \mathrm{wt} \%$ silica and iron oxide fillers have been incorporated. The radiation-induced over crosslinking tendency of the polysiloxane matrix is therefore observed with the filled material. Its $T_{g}$ (measured in DSC) increases linearly with respect to ionizing dose over the studied range, with the same slope as the neat material. Similarly to the neat case, the heat capacity jump associated with the glass transition and its slope decrease with increasing ionizing dose.

However, significant discrepancies have been observed between the evolutions under irradiation of the filled and neat materials.

DMA showed (Fig. 2) that the variation of conservative shear modulus on the rubber plateau of the filled material was 2.5 times greater than that of the neat material at $9.810^{5} \mathrm{~Gy}$. Similarly, the increase in crosslink density of the filled material measured by swelling tests (Fig. 9) was more pronounced than with the neat material.

In ${ }^{29} \mathrm{Si}$ NMR SP-MAS spectra, the increase in the peak at $-67 \mathrm{ppm}$ (T-type crosslinks) and the decrease in the peak at $-47 \mathrm{ppm}$ (phenyl side groups) are attributed to the polymer matrix evolution under irradiation, as they are indeed coherent with the results obtained with the neat samples. However, the filled spectra revealed a significant increase $(\sim 230 \%)$ in the area of the peak at $-107 \mathrm{ppm}$ associated with silica-type units $\left(\mathrm{SiO}_{4}\right)$. As a first 
approximation, one can consider that the samples were exposed to ionizing dose levels which have a negligible impact on the chemical structure of silica fillers ( $\mathrm{SiO}_{4}$ bonds). Therefore, two mechanisms could account for the increase in the $-107 \mathrm{ppm}$ peak: either the polymer matrix progressively turns into a form of silica, or a radiation-induced process taking place at the polymer-fillers interfaces leads to an increase in $\mathrm{SiO}_{4}$ units.

The former hypothesis is contradicted by the ${ }^{29} \mathrm{Si}$ NMR SP-MAS spectra of the irradiated neat material (Fig. 4) as no peak at $-107 \mathrm{ppm}$ was observed, regardless of the ionizing dose level the samples had been exposed to. Matrix-filler interfacial processes are thus most likely to explain the increase in the $-107 \mathrm{ppm}$ peak observed with the filled material.

The main problem with the characterization of this interfacial process is the filler contribution to the apparent crosslink density. As shown in Fig. 8, the conservative shear modulus on the rubber plateau measured in DMA is approximately 4 times greater for the pristine filled sample than for the pristine neat sample. This difference is partly the consequence of a composite effect due to the mixing of high modulus particles with a low modulus rubbery matrix, but also to interactions between them. Polmanteer [38] suggested that in the case of silica fillers, this interaction would be mainly related to physical forces (hydrogen and Van der Waals bonding) with possible chemical bonding upon vulcanization. The ammonia-modified swelling tests in toluene are supposed to disrupt hydrogen bonding. Their results were compared in Fig. 8 with the results in toluene only. They showed that the addition of ammonia had no significant effect on the apparent crosslink density of the pristine neat material while it induced a $500 \%$ increase in the case of the pristine filled sample.

Eq. (6) theoretically links $M_{c}$ to the conservative shear modulus $\mathrm{G}^{\prime}$ on the rubber plateau of an elastomer [39]. It derives from the statistical treatment of a perfect three-dimensional network, based on simplifying assumptions that consist in ignoring the network imperfections. Firstly, it does not take into account the rubber terminal chains that do not contribute to network elasticity (for practical rubbers, the number of such loose ends is negligible [39]). Secondly, the contribution of physical entanglements to the network elasticity (similar to chemical crosslinks) is neglected. However, in most cases, Eq. (6) accurately describes the increase in $\mathrm{G}^{\prime}$ with increasing degree of crosslinking, but absolute values of $\mathrm{G}^{\prime}$ should be treated cautiously due to the simplifying assumptions.

$G^{\prime} \approx \frac{\rho R T}{M_{C}}$

where $\rho$ is the density of the material, $R$ the gas constant and $T$ the temperature.

According to this relationship, the $\mathrm{G}^{\prime}$ ratio of filled to neat materials calculated from $\mathrm{M}_{\mathrm{c}}$ obtained in ammonia swelling tests is approximately 5 , that is the same order of magnitude as the $\mathrm{G}^{\prime}$ ratio from DMA results (approximately 4). Thus, it can be concluded that hydrogen bonding contribution is major to the apparent crosslink density of the filled material, while the remaining difference of $M_{c}$ between the neat and filled pristine materials may be attributed to $\mathrm{SiO}_{4}$-type chemical bonds formed during the initial vulcanization step (curing at $100{ }^{\circ} \mathrm{C}$ ).

Contrary to DMA, the hydrogen bonding contribution mainly linked to the apparent crosslink density can therefore be neglected with the modified swelling tests. The inset of Fig. 9 shows that the degree of crosslinking of the filled sample increases more than that of the neat one. Given that hydrogen bonding contribution to $\mathrm{M}_{\mathrm{c}}$ has been made negligible by the addition of ammonia, the densification of $\mathrm{SiO}_{4}$-type chemical bonds at the matrix-silica fillers interface is the most probable explanation for this observed discrepancy. Moreover, this hypothesis is coherent with the increase in the $-107 \mathrm{ppm}$ peak observed with increasing ionizing dose on the NMR spectra (Fig. 6).

In Fig. 10 is presented another way of interpreting the swelling tests results from Fig. 9. The ordinates chosen are the relative difference between the $\mathrm{M}_{c}$ obtained from swelling tests in toluene only and in the toluene-ammonia solution. When this ratio tends to 1 , the sample swelling in toluene only is negligible compared to its swelling in the ammonia-toluene solution. When it tends to 0 , the addition of ammonia has no effect compared to swelling performed in toluene only. In other words, it accounts for the hydrogen bonds disrupting efficiency of the addition of ammonia to the toluene swelling bath. This efficiency decreases with increasing ionizing dose, from 0.8 down to 0.1 , meaning that for highly irradiated samples, the addition of ammonia has very little effect on $\mathrm{M}_{\mathrm{c}}$. Radiation-induced network crosslinking implies the progressive replacement of hydrogen bonds at the silica filler-polymer matrix interfaces with covalent $\mathrm{SiO}_{4}$ bonds. As a result, less hydrogen bonds are available to be disrupted by the addition of ammonia, therefore decreasing its efficiency.

\section{Conclusion}

Physicochemical analysis evidenced that both the studied filled silicone rubber and its isolated polymer matrix predominantly crosslink when exposed to high energy electron irradiation. Solidstate ${ }^{29} \mathrm{Si} \mathrm{NMR}$ spectroscopy allowed the identification of T-type units $\left(\mathrm{SiO}_{3}\right)$ as the main crosslinks formed under irradiation in the polysiloxane matrix. The combination of ${ }^{29} \mathrm{Si}$ NMR and ammoniamodified swelling tests led to the conclusion that Q-type units $\left(\mathrm{SiO}_{4}\right)$ chemical crosslinks are formed at the silica filler-matrix interfaces, progressively replacing the initial hydrogen bonding evidenced in the pristine samples. These additional chemical crosslinks induce a more pronounced evolution of mechanical properties (shear modulus) in the filled material compared to the isolated polysiloxane matrix. It is believed that they also affect other physical properties critical in space applications. In particular, the influence of these filler-related crosslinks on the electrical properties of such rubbers (studied by the authors for the pristine state [40]) is currently being investigated so as to establish empirical structure-property relationships.

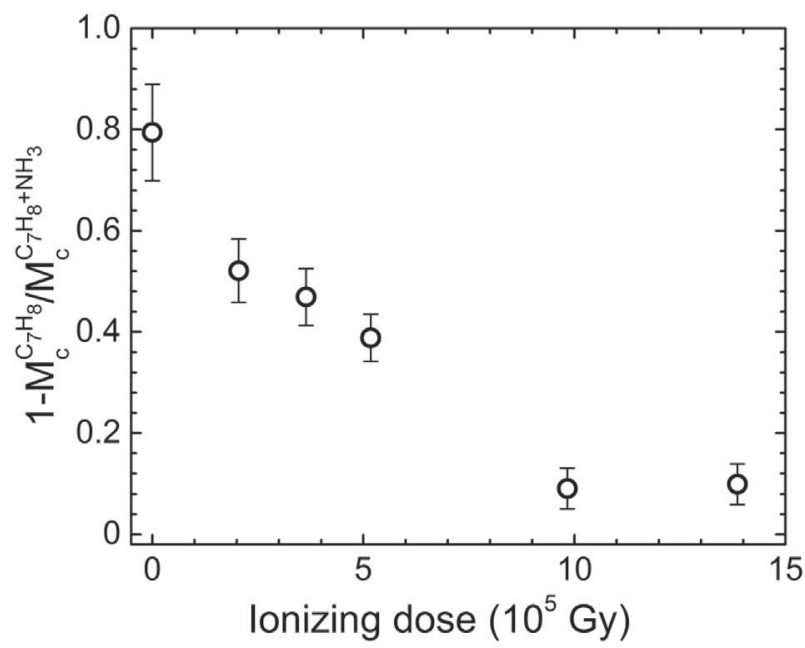

Fig. 10. Influence of ionizing dose on hydrogen bonding disrupting effect of the ammonia solution, for swelling tests performed on filled samples. 


\section{Acknowledgments}

The authors wish to thank Y. Coppel from Laboratoire de Chimie de Coordination (Toulouse, France) for performing the solid-state NMR experiments presented in this paper.

\section{References}

[1] M. Tafazoli, A study of on-orbit spacecraft failures, Acta Astronaut. 64 (2009) 195-205.

[2] M. Cho, Failure mechanisms and protection methods of spacecraft power system, Proc. 2005 Int. Symp. Electr. Insul. Mater. 1 (2005) 45-48 (Kitakyushu).

[3] M. Biron, Silicones ou siloxanes: applications, Tech. l'ingénieur (2007). N2882.

[4] E.L. Warrick, Effects of radiation on organopolysiloxanes, Ind. Eng. Chem. 47 (1955) 2388-2393.

[5] R.S. Maxwell, R. Cohenour, W. Sung, D. Solyom, M. Patel, The effects of $\gamma$-radiation on the thermal, mechanical, and segmental dynamics of a silica filled, room temperature vulcanized polysiloxane rubber, Polym. Degrad. Stab. 80 (2003) 443-450.

[6] A. Labouriau, C. Cady, J. Gill, J. Stull, D. Ortiz-Acosta, K. Henderson, V. Hartung, A. Quintana, M. Celina, Gamma irradiation and oxidative degradation of a silica-filled silicone elastomer. Polym. Degrad. Stab. 116 (2015) 62-74.

[7] A.S. Palsule, S.J. Clarson, C.W. Widenhouse, Gamma irradiation of silicones, J. Inorg. Organomet. Polym. Mater. 18 (2008) 207-221.

[8] B. Schnyder, T. Lippert, R. Kötz, A. Wokaun, V.-M. Graubner, O. Nuyken, UVirradiation induced modification of PDMS films investigated by XPS and spectroscopic ellipsometry, Surf. Sci. 532-535 (2003) 1067-1071.

[9] S. Siegel, T. Stewart, Vacuum-ultraviolet photolysis of polydimethylsiloxane. Gas yields and energy transfer, J. Phys. Chem. 73 (1969) 823-828.

[10] L.E. St Pierre, H.A. Dewhurst, A.M. Bueche, Swelling and elasticity of irradiated polydimethylsiloxanes, J. Polym. Sci. 36 (1959) 105-111.

[11] L.X. Zhang, S.Y. He, Z. Xu, O. Wei, Damage effects and mechanisms of proton irradiation on methyl silicone rubber, Mater. Chem. Phys. 83 (2004) 255-259.

[12] M. Di, S. He, R. Li, D. Yang, Radiation effect of $150 \mathrm{keV}$ protons on methyl silicone rubber reinforced with MQ silicone resin, Nucl. Instrum. Methods Phys. Res. Sect. B Beam Inter. Mater. Atoms 248 (2006) 31-36.

[13] A. Charlesby, in: D. Clegg, A. Collyer (Eds.), The Effects of Ionising Radiation on Polymers Irradiation Effects on Polymers, Elsevier Applied Science, London, 1991, pp. 39-78.

[14] A. Charlesby, Changes in silicone polymeric fluids due to high-energy radiation, Proc. R. Soc. A Math. Phys. Eng. Sci. 230 (1955) 120-135.

[15] J.G. Drobny, Ionizing Radiation and Polymers: Principles, Technology, and Applications, William Andrew, 2012.

[16] A.A. Miller, Radiation Chemistry of Polydimethylsiloxane. 1 I. crosslinking and gas yields, J. Am. Chem. Soc. 82 (1960) 3519-3523.

[17] J.-P. Cohen-Addad, Polymères: la matière plastique (Paris: Belin), 2007.

[18] L. Bokobza, Elastomeric composites. I. Silicone composites, J. Appl. Polym. Sci. 93 (2004) 2095-2104.

[19] J. Xu, K.M. Razeeb, S. Roy, Thermal properties of single walled carbon nanotube-silicone nanocomposites, J. Polym. Sci. Part B Polym. Phys. 46 (2008) 1845-1852

[20] K.P. Sau, D. Khastgir, T.K. Chaki, Electrical conductivity of carbon black and carbon fibre filled silicone rubber composites, Die Angew. Makromol. Chem. 258 (1998) 11-17.

[21] I. Stevenson, L. David, C. Gauthier, L. Arambourg, J. Davenas, G. Vigier, Influence of SiO2 fillers on the irradiation ageing of silicone rubbers, Polym. Guildf. 42 (2001) 9287-9292.

[22] M. Patel, P.R. Morrell, J.J. Murphy, A. Skinner, R.S. Maxwell, Gamma radiation induced effects on silica and on silica-polymer interfacial interactions in filled polysiloxane rubber, Polym. Degrad. Stab. 91 (2006) 406-413.

[23] H. Jochem, V. Rejsek-Riba, E. Maerten, S. Remaury, S. Solé, G. Sierra, A. Baceiredo, O. Guillaumon, Effects of $400 \mathrm{keV}$ electrons flux on two space grade silicone rubbers, Mater. Chem. Phys. 141 (2013) 189-194.

[24] A. Chien, R Maxwell, D. Chambers, B. Balazs, J. LeMay, Characterization of radiation-induced aging in silica-reinforced polysiloxane composites, Radiat. Phys. Chem. 59 (2000) 493-500.

[25] K.E. Polmanteer, C.W. Lentz, Reinforcement Studies-Effect of Silica Structure on Properties and Crosslink Density, Rubber Chem. Technol. 48 (1975) 795-809.

[26] P.J. Flory, J. Rehner, Statistical Mechanics of Cross-Linked Polymer Networks II. Swelling, J. Chem. Phys. 11 (1943) 521-526.

[27] E. Favre, Swelling of crosslinked polydimethylsiloxane networks by pure solvents: Influence of temperature, Eur. Polym. J. 32 (1996) 1183-1188.

[28] H. Demers, N. Poirier-Demers, A.R. Couture, D. Joly, M. Guilmain, N. de Jonge, D. Drouin, Three-dimensional electron microscopy simulation with the CASINO Monte Carlo software, Scanning 33 (2011) 135-146.

[29] A. Sicard-Piet, S. Bourdarie, D. Boscher, R.H.W. Friedel, M. Thomsen, T. Goka, $\mathrm{H}$. Matsumoto, H. Koshiishi, A new international geostationary electron model: IGE-2006, from $1 \mathrm{keV}$ to $5.2 \mathrm{MeV}$, Space Weather 6 (2008) S07003.

[30] A. Chapiro, Radiation Chemistry of Polymeric Systems, Interscience publishers, 1962.

[31] A.M. Bueche, An investigation of the theory of rubber elasticity using irradiated polydimethylsiloxanes, J. Polym. Sci. 19 (1956) 297-306.

[32] D.J. Hill, C.M. Preston, A.K. Whittaker, NMR study of the gamma radiolysis of poly(dimethyl siloxane) under vacuum at 303K, Polym. Guildf. 43 (2002) 1051-1059.

[33] G. Deshpande, M.E. Rezac, The effect of phenyl content on the degradation of poly(dimethyl diphenyl) siloxane copolymers, Polym. Degrad. Stab. 74 (2001) $363-370$.

[34] E. Lippmaa, M. Maegi, A. Samoson, G. Engelhardt, A.R. Grimmer, Structural studies of silicates by solid-state high-resolution silicon-29 NMR, J. Am. Chem. Soc. 102 (1980) 4889-4893.

[35] D. Fragiadakis, P. Pissis, Glass transition and segmental dynamics in poly(dimethylsiloxane)/silica nanocomposites studied by various techniques, J. Non. Cryst. Solids 353 (2007) 4344-4352.

[36] C.G. Delides, I.W. Shepherd, Dose effects in the crosslinking of irradiated polysiloxane, Radiat. Phys. Chem. 10 (1977) 379-385.

[37] M.J. Duer, Solid State NMR Spectroscopy: Principles and Applications, Blackwell, Oxford, 2002.

[38] K.E. Polmanteer, Current perspectives on silicone rubber technology, Rubber Chem. Technol. 54 (1981) 1051-1080.

[39] L.R.G. Treloar, The Physics of Rubber Elasticity, Oxford University Press, USA, 1975.

[40] A. Roggero, E. Dantras, T. Paulmier, C. Tonon, N. Balcon, V. Rejsek-Riba, S. Dagras, D. Payan, Electrical behaviour of a silicone elastomer under simulated space environment, J. Phys. D. Appl. Phys. 48 (2015) 135302. 